INTERNATIONAL DESIGN CONFERENCE - DESIGN 2018

https://doi.org/10.21278/idc.2018.0225

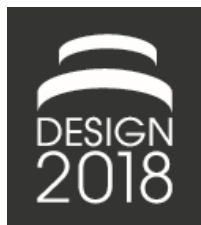

\title{
USING THE POTENTIALS OF ADDITIVE MANUFACTURING BY A SYSTEMATIC LINKAGE OF THE MANUFACTURING PROCESS TO PRODUCT DESIGN
}

\author{
J. Würtenberger, J. Reichwein and E. Kirchner
}

\begin{abstract}
This paper shows a way for a systematic linkage of knowledge about additive manufacturing to the development process using a design pattern matrix. The potentials of additive manufacturing are demonstrated by defining manufacturing induced properties. These properties gives the designer new stimulations to extend potential solution variants to concretize function carriers for a given task during the development process.
\end{abstract}

Keywords: additive manufacturing, design methodology, characteristics and properties, function carrier

\section{Introduction}

The market for additive manufacturing is growing and is expected to continue growing for the next several years (Wohlers, 2015). In the beginning it was used for rapid prototyping only, then through an improvement of quality of the produced parts it was possible to manufacture tools and nowadays additive manufacturing is able to produce finished goods (Gibson et al., 2015). To optimize manufacturing of products it is necessary to consider the manufacturing process. There are already many approaches in Design for Manufacturing (DfM), but they are not transferable to Design for additive Manufacturing (DfaM). Because of the increasing potentials of the additive manufacturing processes it is essential to review if the current processes can be replaced by AM to improve product quality, functionality, customizability or to reduce manufacturing costs and production time. In Addition a lot of literature is focusing on the advantages of additive manufacturing compared to conventional production (e.g. Thompson et al., 2016). To use this advantages of AM it is required to adapt the design of the existing products. It is necessary to change the geometry, reduce the number of parts, consolidate parts or use a different structure (e.g. lightweight, crash absorbing) to profitable replace a conventional manufacturing process by additive manufacturing. But there is still no systematic approach for the designer how to use this advantages while (re)designing the product. Hence there are lots of opportunities to improve products through extensive use of additive manufacturing.

Lindemann et al. presented a methodology to the selection of part candidates for additive manufacturing and an approach for redesigning them to suit the requirements of AM (Lindemann et al., 2015). The mind-set of the designer has to be different whether he designs additive manufactured products or products that are made by turning or milling operations. So far there is still no approach that examines the potentials from the process side. Therefore this paper presents a systematic approach for adapting an existing product regarding functionality, quality, costs and production time while offering a comprehensive customizability and using the full potential of additive manufacturing. This is achieved 
by questioning conventional production and assembly restrictions that are not applying to additive manufacturing. The design of the products can be more geared to functional fulfilment, because fewer manufacturing restrictions have to be taken into account. Hence it is possible to improve the products during an adaptive redesign.

\section{The development process}

As mentioned in the introduction, AM offers much potential to improve products. In order to support the designer during the improving process, this paper presents a systematic approach to use this potentials while redesigning products. As a foundation for this methodology it is necessary to explain the authors' understanding of the product development process first.

The product development process is characterized by a stepwise concretization from a product idea to a detailed product design. Pahl et al. as well as VDI 2221 divides the development process into four phases: Clarifying the task, conceptual design, embodiment design and detail design (VDI 2221, 1993; Pahl et al., 2007), see Figure 2.

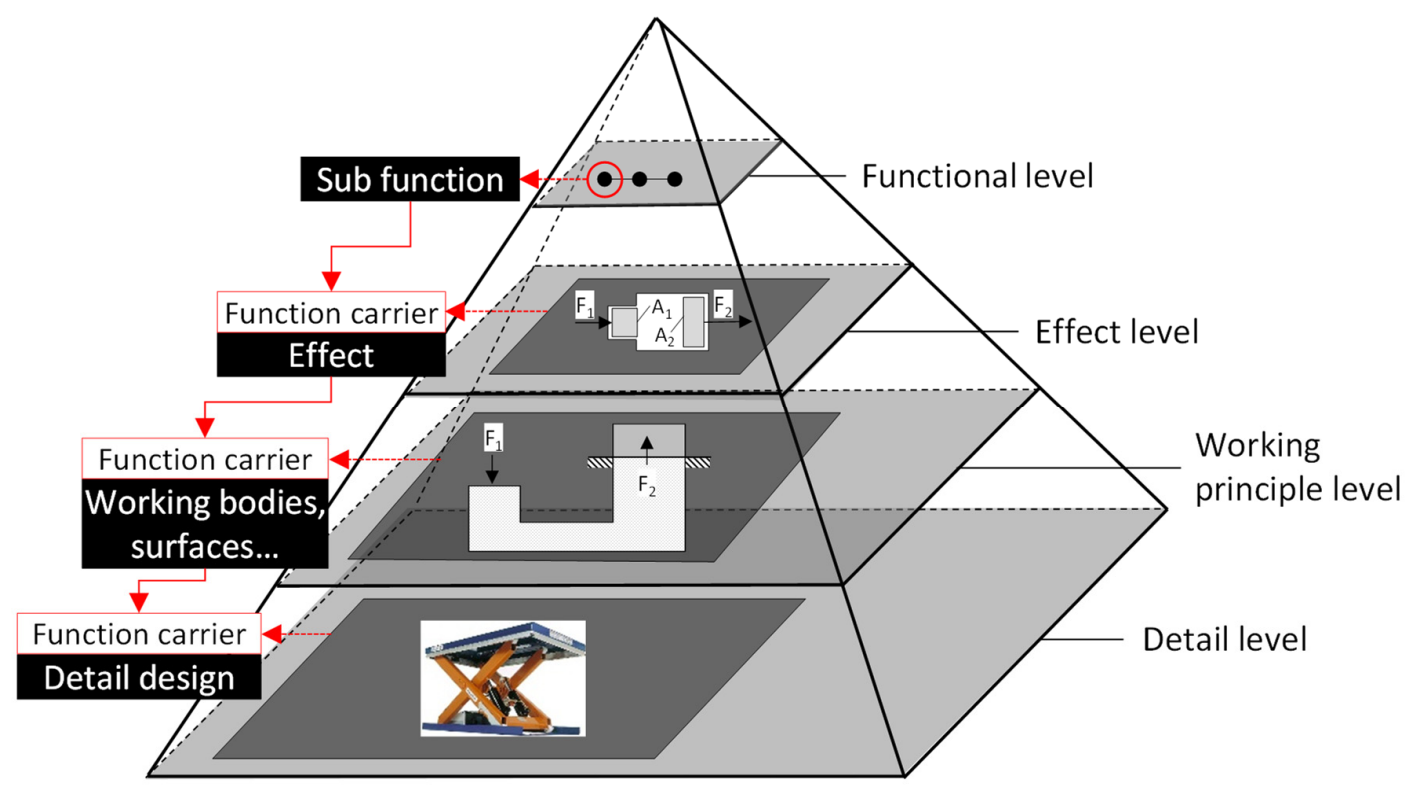

Figure 1. Pyramid of the product models (adapted from Ehrlenspiel and Meerkamm, 2013)

At the early phases, the task is clarified by defining requirements of the task which results from the product idea. After that, the product functions are determined in order to fulfil the given task. All defined sub-functions are then concretized by solution principles, which are detailed during the embodiment and detail design phases until the final design of the product is set.

The results of the stepwise concretization of the product is described for example with the help of the pyramid of the product models, see Figure 1. The pyramid contains product models with different levels of abstraction. At the functional level, the product is objectively described with the help of subfunctions, which are necessary to be conform to the requirements. After this, the sub-functions are concretised by means of physical, chemical or biological effects (Lindemann, 2007). At the working principle level, the effects are combined with material and geometrical parameters, for example by defining working geometry, working surfaces, working location and working motions (Pahl et al., 2007), so a general solution to the task is given. At least, all information of the active principle model is specified at the detail design level until the final design of the product is done. It can be seen that the fulfilment of the functions is realized by so called function carriers. They describe the elements necessary for realising a sub-function and can be applied at the different levels of concretisation of the pyramid. In Figure 1, the concretization of a hydraulic lifting platform is described, which is the detail 
design from the sub-function increase a manual force by using the effect pressure transmission, see Figure 1.

During these phases, the designer has to consider two principle limitations: On the one hand, the stepwise concretisation of the product has to fulfil the requirements of the costumer as good as possible. Therefore the designer can use design guidelines or design rules to generate a large field of solution variants in order to find out the one which fits best during each concretization step. On the other hand the designer has to consider manufacturing and assembly restrictions in order to ensure the manufacturability of the product, wherefore he can use general approaches like Design for Manufacture (DfM), Design for Assembly (DfA) or Design for Manufacture and Assembly (DfMA) as well as a huge number of rules (Pahl et al., 2007), guidelines (Bralla, 1999; Boothroyd et al., 2010) or design references (Roth, 2000), see Figure 2.

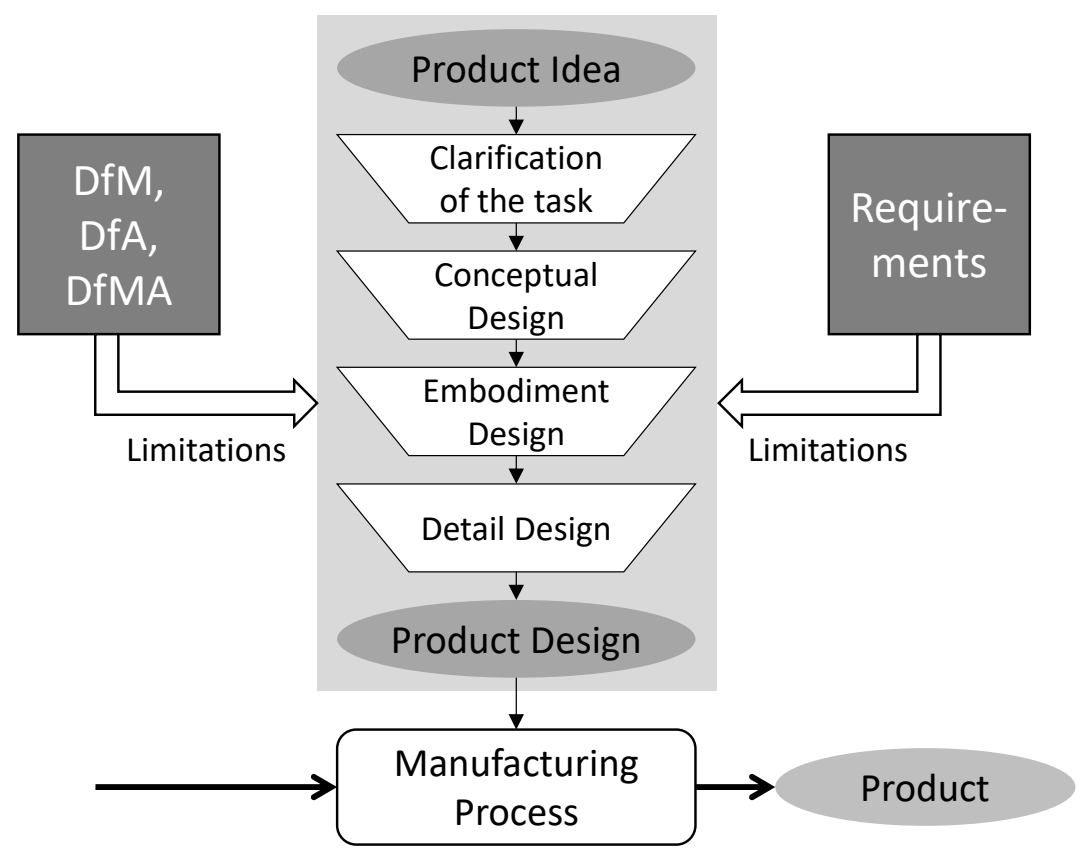

Figure 2. Limitations during the development process (adapted from Monnerjahn et al., 2017; VDI 2221, 1993)

Both limitations have to be considered in parallel and cause conflicts of interests, so the optimal product function, concept, embodiment or detail design to fulfil the requirements cannot be realized because of the manufacturing driven limitations. The designer goes through many iteration loops during the development process of a product in order to find the best trade-off between the best fitting product for the requirements and its manufacturability.

Additive manufacturing has the potential to minimize the manufacturability driven limitations. Therefore, the potentials have to be integrated into the creation of solution variants during the phases of the product development process, wherefore process integrated design guidelines are used in literature (e.g. Wagner et al., 2016).

These guidelines prepare the process knowledge of a certain manufacturing technology to describe principle solutions which can be achieved using that technology. The principle solutions are described by manufacturing induced design elements and corresponding induced properties. For example by using the high speed cutting technology, a design element is to cut a notch into a part and the manufacturing induced properties are the notch position and the notch geometry, see Figure 3 (Wagner et al., 2016). The principal solutions of a certain technology are confronted with the function carriers of the design process as well as with the required properties of the carriers in a so called design pattern matrix. The function carriers can be filled into the matrix on different levels of abstraction as shown in Figure 1. 


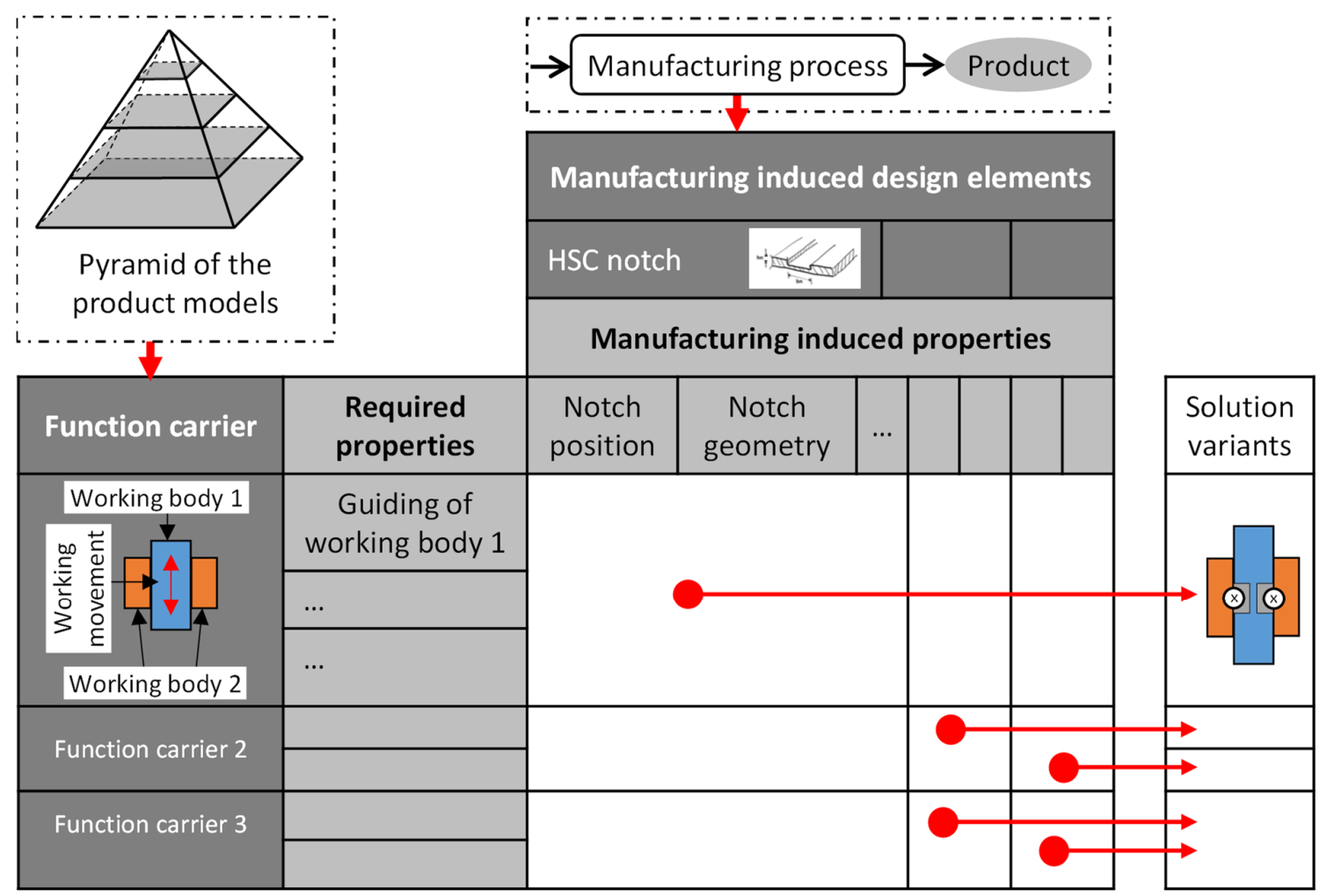

Figure 3. Design pattern matrix (adapted from Wagner et al., 2016)

The next step is to generate solution variants that realize the function carriers by a systematized matching with the manufacturing design elements, whereby the defined required and induced properties give the designer intellectual stimulations, see Figure 3.

For example if the designer has to design a guidance and a principle product model is already set, see Figure 3, he can use for example the manufacturing induced design element HSC notch in order to create a solution variant for a guidance using a notch and rolling elements.

After that, the designer evaluate the solution variants in order to find the best trade-off between the two limitations.

\section{The AM design pattern matrix}

The idea of a design pattern matrix to use the potentials of a manufacturing technology is now adapted to additive manufacturing. The potentials of the technology are described first and then corresponding manufacturing induced design elements are defined and described in a design pattern matrix.

\subsection{Potentials of additive manufacturing}

The Design Pattern Matrix shows the potentials of AM as manufacturing induced design elements. These are mainly the choice of material, the geometry and the topology of the components. The design elements cause specific manufacturing induced properties, such as surface roughness, stiffness of the structure or colour of the component.

\subsubsection{Materials}

There are already a lot of different materials that can be printed, for example different steel and aluminium alloys, thermoplastic and thermosetting polymers and even paper. Especially the combination of materials with different properties for example electrical conductive and insulation materials is promising. In addition, a combination of different coloured materials can be created for design reasons or used for marking and labelling of products, see Figure 4. 


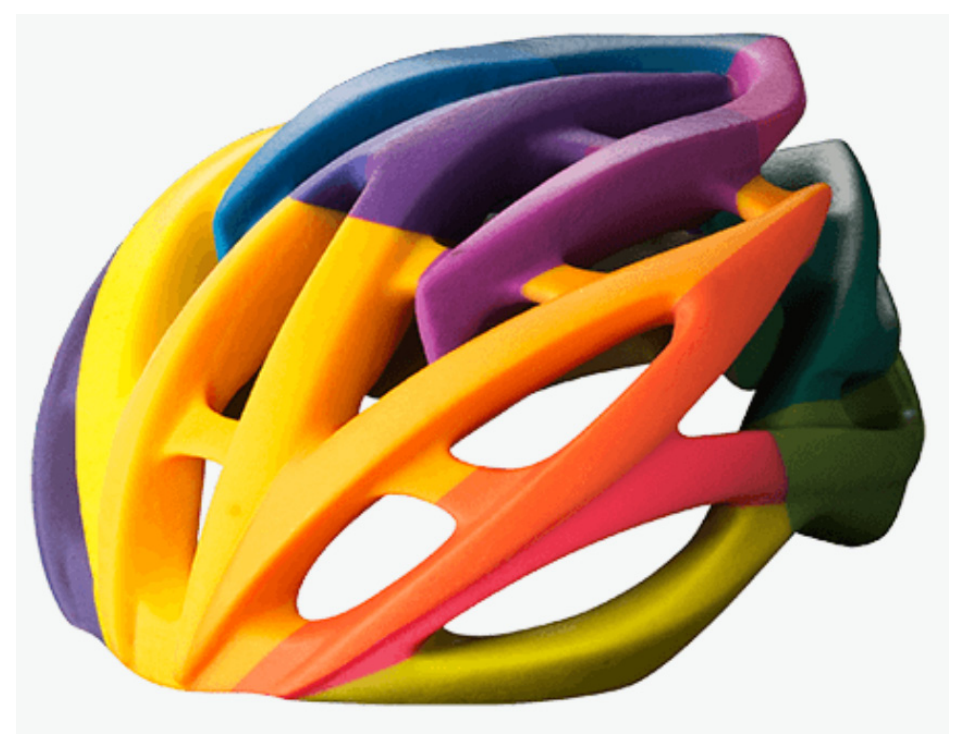

Figure 4. Customized helmet (Stratasys, 2017)

The choice of the material influences a lot of properties of the final product, for example the stiffness, heat transfer and the surface roughness. But the surface is not only affected by the type of material. A common material for selective laser melting (SLM) is the aluminium alloy AlSi10Mg. Experiments with that alloy showed, that also the grain size of the powder and the laser power influences the surface texture. The surface roughness varies between $14 \mu \mathrm{m}$ and $24 \mu \mathrm{m}$ by changing scan speed and hatching distance (Townsend et al., 2016). Also there is a difference in the surface roughness between horizontal and vertical surfaces depending on the print-direction. Figure 5 shows a rough surface on the lateral surface that is parallel and an even surface perpendicular to the print-direction. These manufacturing induced properties should be used beneficial to fulfil the required properties of the function carriers.

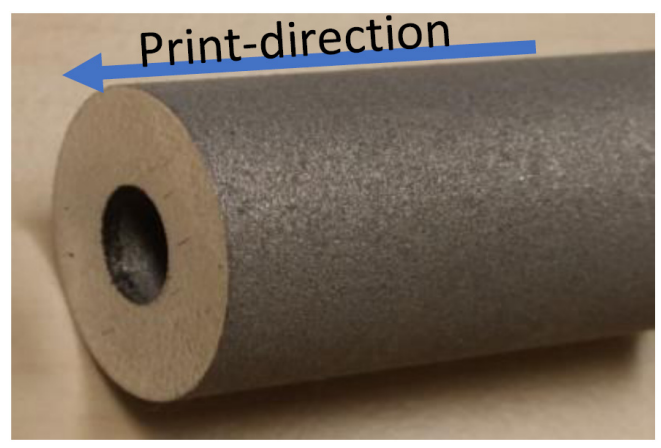

Figure 5. Comparison between surfaces parallel and perpendicular to print-direction

\subsubsection{Geometry}

The most significant advantage of Additive Manufacturing is the freedom in geometry. There are almost no limits in complexity of the parts that can be produced. The restrictions through the manufacturing process are much less than in conventional production. Therefore the products can be more functionoriented. The potential to produce complex geometries like freeform surfaces is already used in many areas for example in art or fashion (Doubrovski et al., 2011). But also applications for which weight is a decisive factor, for example the aviation industry, uses AM to optimize their products. The use of topology optimization is an opportunity to find the best structure for a given load case. This allows to 
reduce the weight of components and therefore save fuel during the use phase. The topology optimization often results in a bionic structure that is not producible by conventional manufacturing processes (EOS, 2015).

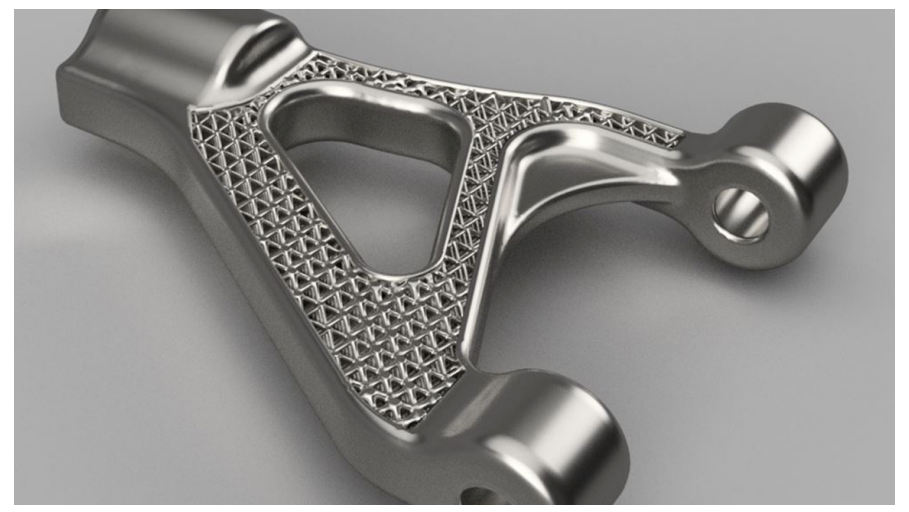

Figure 6. Internal lattice structure (Autodesk, 2017)

The inner geometry is not restricted by the shape of tools, because it is not necessary to remove material by drilling or milling. Hence additive manufactured parts can have an arbitrary inner geometry. Holes for example do not have to be rotationally symmetrical, it is possible to change the cross section and to produce undercuts. This can be used to produce micro structures that are built up from unit cells, see Figure 6 and Figure 7. Just a fraction of the volume is filled up with solid material, which decreases the weight of the parts further on. In biomedical usages this micro structures can be optimized for cell attachment and growth (Watts and Hague, 2006).

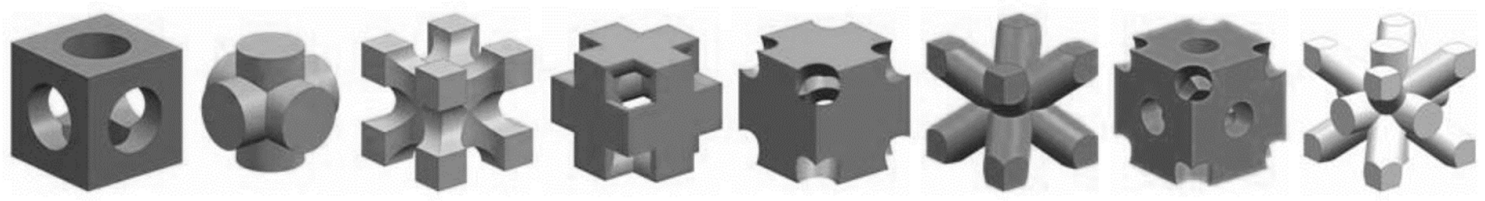

Figure 7. Possible unit cells with a volume fraction of $50 \%$ (Watts and Hague, 2006)

\subsubsection{Topology of components}

As much more complex geometries can be produced, several components can be combined into one when adapting an existent design to additive manufacturing. This reduces the number of components and therefore saves assembly and storage costs. Through the choice of electrical conductive and isolating material it is possible to print a Dielectric Elastomer (DE) sensor in one part. Figure 8 shows a DE force sensor printed with thermoplastic polyurethane (TPU) as dielectric material and carbonfilled polyactic acid (PLA) as electrode material. The white part of the sensor is TPU and the black part is the conductive PLA. Embedded in a product it is possible to monitor the force flow in this component. Beyond the consolidation of components the production of already assembled parts holds further potential.

Due to the increasing competition there is a big demand for customization of products. In contrast to conventional manufacturing it is simple to change the geometry of the produced part and add an individual embossing or fulfil customer requirements regarding the colour of the product. While the base of the product stays the same there are some features that are customized and tailored to the customers wishes. 


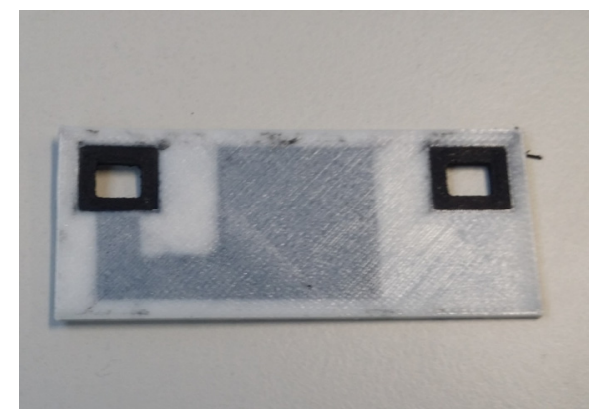

Figure 8. 3D printed Dielectric Elastomer sensor developed at Fraunhofer LBF Darmstadt

\subsection{Manufacturing induced design elements}

The manufacturing induced design properties are derived from the design elements. As described in the previous chapter the design elements of additive manufacturing are material, geometry and the topology of the components. Figure 9 shows the head of the design pattern matrix with the manufacturing induced design elements and the associated properties.

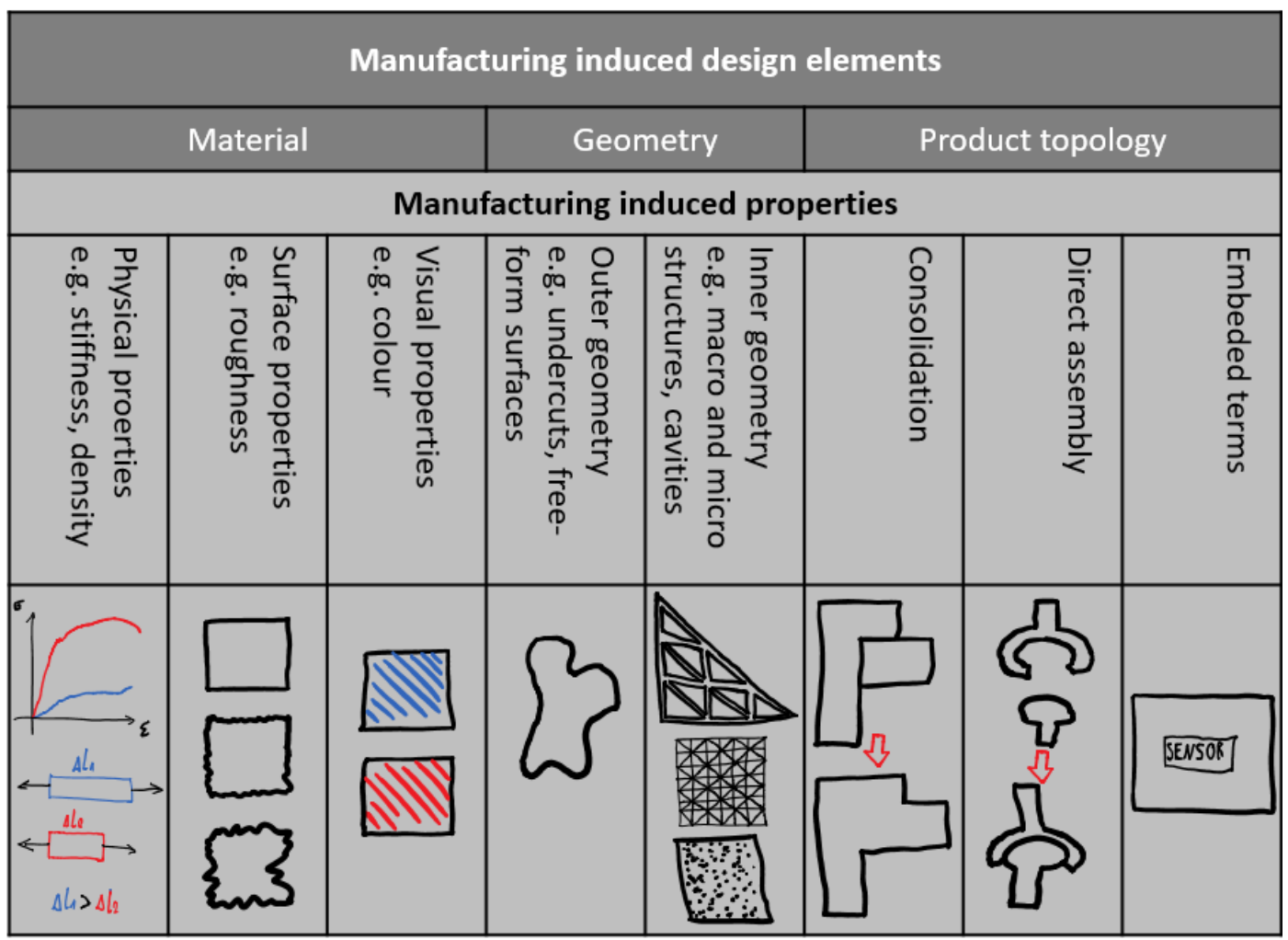

Figure 9. Systematized potentials of additive manufacturing

The last row shows some simple graphical examples, which contributes to finding new and innovative solutions. The choice of material concludes to physical properties like stiffness or density, surface properties like roughness and visual properties like the colour of the product. Geometrical properties are divided in outer and inner geometry. Additive manufacturing enables the production of complex freeform surfaces and undercuts on the outside, which are hard to manufacture with conventional methods. Beyond that it is possible to use truss and lattice structures or porosity in the material. Changes in the product topology holding the greatest potential, but are also hard to realize. Especially the consolidation of several parts into one can have a big impact on production costs and quality. 


\section{Adaptive design of an injection moulding tool using the AM design pattern matrix}

In the following section it is demonstrated how a product can be improved using the AM design pattern matrix. The initial point is a concept of an injection moulding tool as shown in Figure 10. It consists of a lower part which contains an injection nozzle to fill the mould cavity with the material as well as cooling channels to dissipate the heat. The platen as well as the ejector pins can move upwards until the vertical range of the pins is blocked. The platen then moves forwards, whereby the part is ejected.

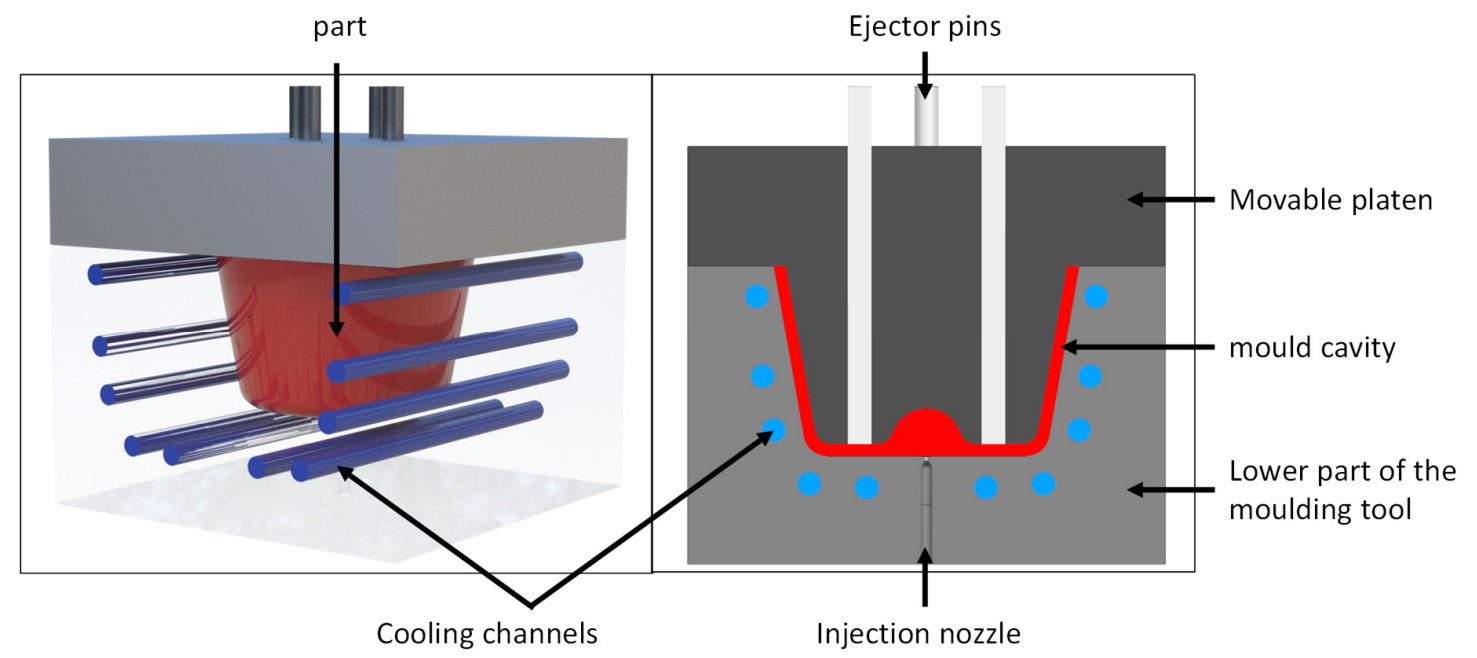

Figure 10. Injection moulding tool

To prepare the application of the AM design pattern matrix, the function carriers of the moulding tool are defined.

\subsection{Function carriers}

The injection moulding tool consists of the four sub-functions filling, provide a shape, cooling and ejection which have to be fulfilled to satisfy the requirements. The concept is concretized to the working principle level and function carriers as well as corresponding elements for realising the sub-functions are defined and the function carriers are set and highlighted in red, see Figure 11.

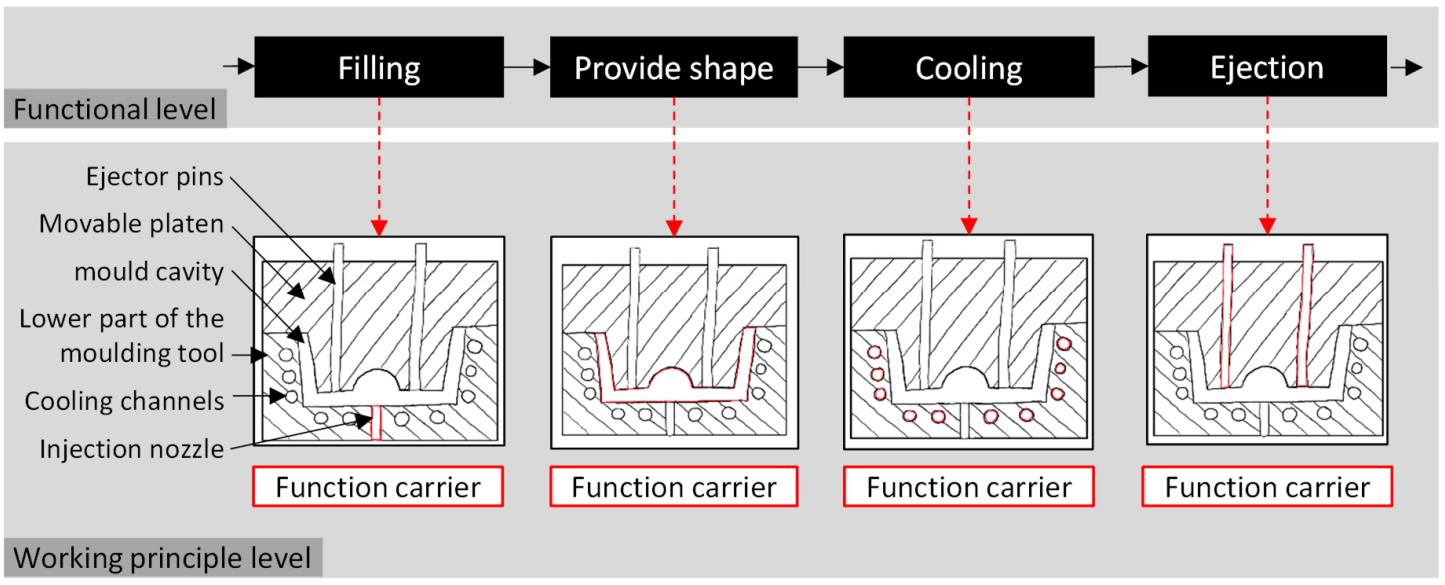

Figure 11. Function carriers of the injection moulding tool

The function filling is realised by the function carrier injection nozzle, providing of the shape by the mould cavity between the movable platen and the lower part of the moulding tool, cooling by the cooling channels in the lower part of the moulding tool and the ejection by the ejector pins. 


\subsection{AM design pattern matrix}

The described function carrier of the injection moulding tool are filled in into the AM design pattern matrix and required properties, see Figure 12.

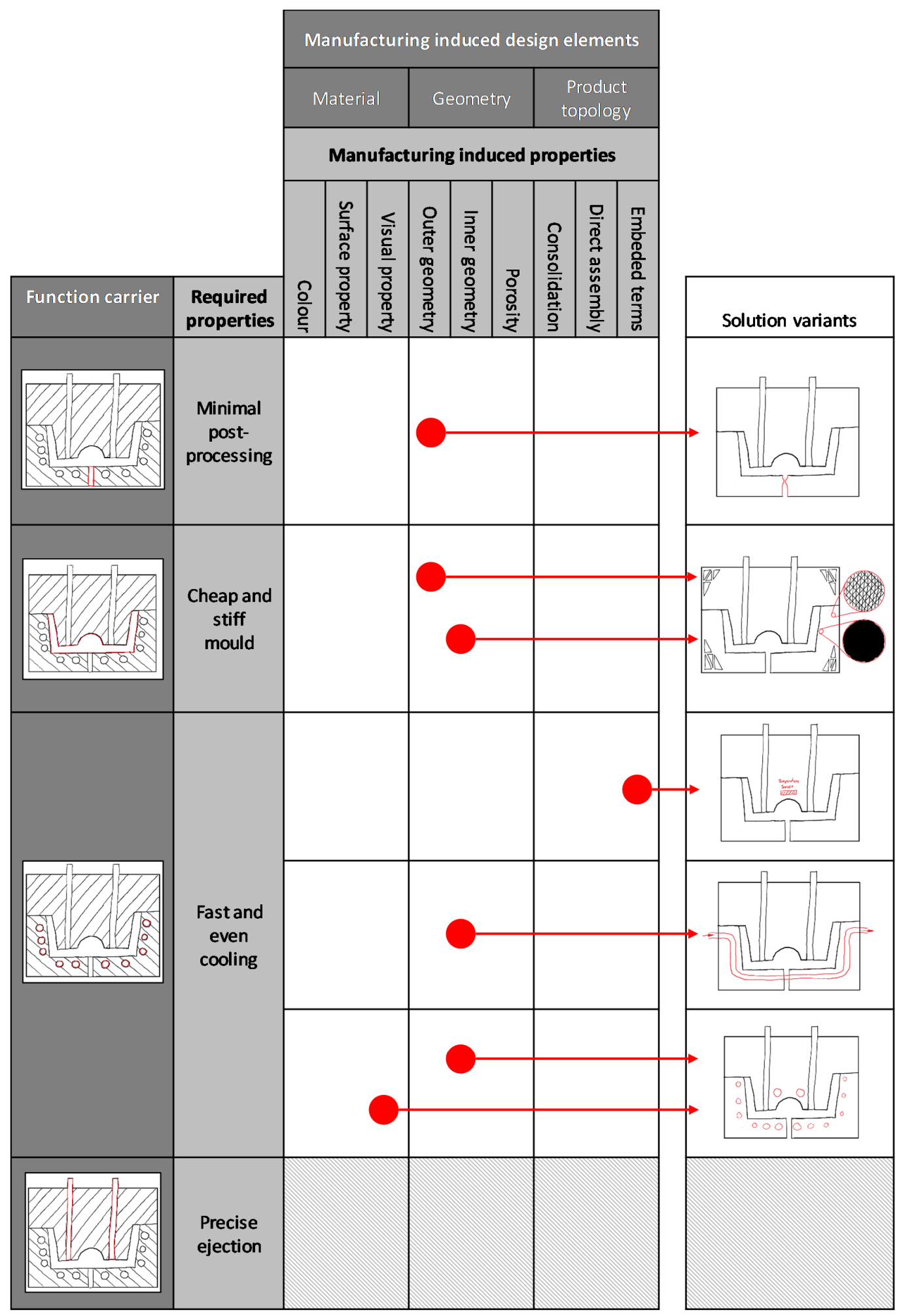

Figure 12. AM- design pattern matrix 
By matching the function carriers with the manufacturing induced design elements, solution variants to improve the function carrier can be defined. Potential solution variants are exemplarily shown in Figure 12. For example to improve the carrier of the filling function, the outer geometry of injection nozzle is adapted, see first row of Figure 12.

With the help of that, the predetermined breaking point is very close to the part and the post processing of the injected parts can be minimized. In order to reduce the cost of the mould material can be saved by a variation of the outer and inner geometry, see second row of Figure 12. Therefore, lattice structures as well as truss structures are integrated at the outer area of the mould to minimize the needed material and ensure a high stiffness.

The cooling of the mould offers much potential to make it faster and more even, see rows 3-5 in Figure 12. It is conceivable to integrate a temperature sensor into the mould in order to regulate the flow volume of the cooling fluid. Furthermore, the geometry of the cooling channels can be varied in a way to realize a contour-dependent cooling. Another solution variant for an improved cooling is the variation of the number, diameter and surface property of the channels to regulate the flow volume of the cooling fluid without the need of any additional control components. For the ejection of the part is no need for an adaption of the pins because of the simple geometry of the part. For more complex parts the geometry of the movable platen as well as guidance and the geometry of the ejection pins is conceivable in order to improve the ejection of the part.

The last step is to combine the solution variants to a principle solution, for example by combining the rows 2, 4 and 5 of the design pattern matrix. The result is shown in Figure 13, which shows in contrast to the initial concept several advantages.

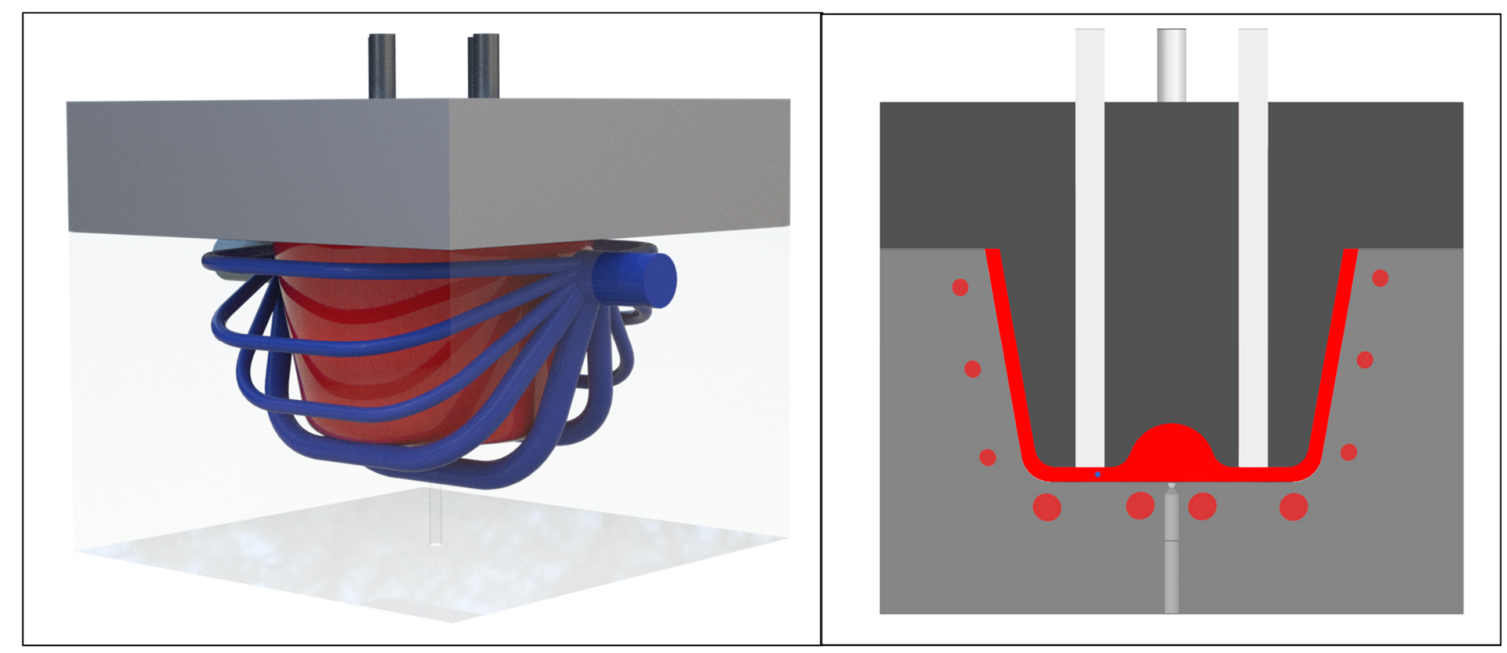

Figure 13. Principal overall solution

First, the cooling of the mould is faster and more even than before. This enables a shorter cycle time and therefore saves costs in production of parts. Through the application of lattice structures in areas with low mechanical load, there is a lower consumption of material, hence the costs for the tool are less. Also the weight of the tool is smaller and therefore the moving part of the injection moulding machine needs less strong actuators for opening and closing the mould. In addition there are several advantages from the AM process: the manufacturing is less complicated, because the drilling and milling process of the concept of Figure 10 is combined by only one process step. Also it is very simple to change some details on the final product and redesign the tool. Beyond this, if a new tool is needed after a few years it can be produced fast and easy direct from the stored CAD model.

\section{Conclusion and outlook}

This paper shows a way for a systematic linkage of knowledge about additive manufacturing to the development process using a design pattern matrix. The potentials of additive manufacturing are 
demonstrated by defining manufacturing induced properties. These properties gives the designer new stimulations to extend potential solution variants to concretize function carriers. The design pattern matrix is used in this paper for an adaptive design, but an application for variant or new-designs is also executable.

In further works, a comparison of the additive manufacturing-driven solution variants to conventional manufacturing technologies is needed in order to find the best fitting concept according to the requirement- and manufacturing driven limitations. Therefore, it could be helpful to adapt the design pattern matrix to a more detailed level in order to face the component properties of conventional and additive manufactured parts to support the designer to decide which manufacturing technology fits best for the given task.

\section{References}

Autodesk (2017), 3D printing software from design to manufacture. [online] Available at: https://www.autodesk.co.uk (accessed 08.12.2017).

Boothroyd, G., Dewhurst, P. and Knight, W.A. (2010), Product Design for Manufacture and Assembly, CRC Press.

Bralla, G. (1999), Design for Manufacturability Handbook, The McGraw-Hill Companies.

Doubrovski, Z., Verlinden, J. and Geraedts, J. (2011), "Optimal Design for Additive Manufacturing: Opportunities and Challenges", Proceedings of the ASME Design Engineering Technical Conference. https://doi.org/10.1115/DETC2011-48131

Ehrlenspiel, K. and Meerkamm, H. (2013), Integrierte Produktentwicklung. Denkabläufe, Methodeneinsatz, Zusammenarbeit, Hanser, München.

EOS (2015), EADS and EOS - Study Demonstrates savings potential for DMLS in the aerospace industry. [online] EOS GmbH. Available at: https://www.eos.info/press/customer_case_studies/eads (accessed 08.12.2017).

Gibson, I., Stucker, B. and Rosen, D. (2015), Additive Manufacturing Technologies, Springer, New York. https://doi.org/10.1007/978-1-4939-2113-3

Lindemann, C., Reiher, T., Jahnke, U. and Koch, R. (2015), "Towards a sustainable and economic selection of part candidates for additive manufacturing", Rapid Prototyping Journal, Vol. 21 No. 2, pp. 216-227. https://doi.org/10.1108/RPJ-12-2014-0179

Lindemann, U. (2007), Methodische Entwicklung technischer Produkte. Methoden flexibel und situationsgerecht anwenden, Springer Berlin, Heidelberg.

Monnerjahn, V., Gramlich, S., Groche, P., Roos, M., Wagner, C. and Weber Martins, T. (2017), "Production Technologies and Product Development”, In: Groche, P., Bruder, E. and Gramlich, S. (Eds.), Manufacturing Integrated Design: Sheet Metal Product and Process Innovation, Springer, Cham, pp. 1-9. https://doi.org/10.1007/978-3-319-52377-4_1

Pahl, G., Beitz, W., Feldhusen, J. and Grote, K.-H. (2007), Konstruktionslehre - Grundlagen erfolgreicher Produktentwicklung; Methoden und Anwendung, Springer, Heidelberg. https://doi.org/10.1007/978-3-540$34061-4$

Roth, K. (2000), Konstruieren mit Konstruktionskatalogen. Band 1: Konstruktionslehre, Springer, Berlin.

Stratasys (2017), Connex3 Object260 - Unleash you creativity. [online] Available at: http://www.stratasys.com/3d-printers/objet260-connex3 (accessed 08.12.2017).

Thompson, M., Moroni, G., Vaneker, T., Fadel, G., Campbell, R.I. et al. (2016), "Design for Additive Manufacturing: Trends, opportunities, considerations, and constraints", CIRP Annals - Manufacturing Technology, Vol. 65 No. 2, pp. 737-760. https://doi.org/10.1016/j.cirp.2016.05.004

Townsend, A., Senin, N., Blunt, L., Leach, R.K. and Taylor, J.S. (2016), "Surface texture metrology for metal additive manufacturing: a review", ScienceDirect Precision Engineering, Vol. 46, pp. 34-47. https://doi.org/10.1016/j.precisioneng.2016.06.001

VDI 2221 (1993), Methodik zum Entwickeln und Konstruieren technischer Systeme und Produkte, BeuthVerlag, Düsseldorf. 
Wagner, C., Roos, M., Gramlich, S. and Kloberdanz, H. (2016), "Process integrated design guidelines systematically linking manufacturing process to product design", Proceedings of the DESIGN 2016 / 14th International Design Conference, Dubrovnik, Croatia, May 16-19, 2016, The Design Society, Glasgow.

Watts, D.M. and Hague, R.J. (2006), "Exploring the design freedom of RM", Proceedings of the 17th Solid Freeform Fabrication Symposium (SFF 2006), Austin, Texas, August 1 -16, 2006, pp. 656-667.

Wohlers, T. (2015), Wohlers Report: Global Reports, Wohlers Associates, Belgium.

Jan Würtenberger, M.Sc.

Technische Universität Darmstadt, Product Development and Machine Elements (pmd)

Magdalenenstrasse 4, 64289 Darmstadt, Germany

Email: wuertenberger@pmd.tu-darmstadt.de 